\title{
Effect of Thermal Aging Conditions on the Corrosion Properties and Hardness of a Duplex Stainless Steel
}

\author{
José Eduardo May ${ }^{\mathrm{a}}$, Carlos Alberto Caldas de Souza ${ }^{\mathrm{b}}$, Pedro Augusto de Paula Nascente ${ }^{\mathrm{c}}$, \\ Paulo Soares ${ }^{\mathrm{d}}$, Carlos Mauricio Lepienski, Sebastião Elias Kuri ${ }^{\mathrm{c}, *}$ \\ aTECHFIVE Gestão de Resíduos, Rod. Geraldo Scavone, 2300, \\ Cond. California Center, CEP 12305-620, Jacareí, SP, Brazil \\ ${ }^{\mathrm{b}}$ Department of Chemical Technology and Materials, Federal University of Bahia, \\ Av. Aristides Novis, 2, Federação, CEP 40210-630, Salvador, BA, Brazil \\ ${ }^{\mathrm{c}}$ Department of Materials Engineering - DEMa, Federal University of São Carlos, \\ Rod. Washington Luis, Km 235, CEP 13565-905, São Carlos, SP, Brazil \\ ${ }^{\mathrm{d}}$ CEFET of Santa Catarina, Unidade Joinville, Coord. Mecânica, \\ Rua Pavão, Costa e Silva, 1337, CEP 89220-200, Joinville, SC, Brazil \\ ${ }^{\mathrm{e}}$ Department of Physics, Federal University of Paraná, \\ Rua Francisco H. dos Santos, Centro Politécnico, Bloco 11, sala 37, \\ CEP 81531-990, Curitiba, PR, Brazil
}

Received: February 11, 2010; Revised: November 17, 2010

\begin{abstract}
The corrosion properties of a $22.5 \mathrm{wt}$. (\%) Cr duplex stainless steel were investigated after long-term aging of 3000, 5000 and 7000 hours at 300 and $400{ }^{\circ} \mathrm{C}$. The corrosion resistance was measured based on mass loss in a $\mathrm{FeCl}_{3} 10 \mathrm{wt}$. (\%) solution and electrochemical measurements in a $0.1 \mathrm{M} \mathrm{H}_{2} \mathrm{SO}_{4}$ solution. The results indicate that the corrosion resistance decreased steadily up to 5000 hours of aging. However, the samples subjected to 7000 hours of aging showed better corrosion resistance than those aged for 3000 and 5000 hours. This effect is attributed to the phase transformation that occurs during aging, a finding which was confirmed by hardness, transmission electron microscopy and X-ray photoelectron spectroscopy measurements.
\end{abstract}

\section{Keywords: duplex stainless steel, corrosion, structural characterization, long-term aging}

\section{Introduction}

Duplex stainless steel has excellent properties in several environments due to its high pitting corrosion and stress-corrosion cracking resistance, along with high mechanical strength, good weldability, and low thermal expansion coefficient ${ }^{1}$. The corrosion resistance of these alloys is the same or higher than that of their austenitic analogues and they have higher strength, enabling gauge, weight and cost reductions ${ }^{2}$. The superior properties of duplex stainless steels, which are mainly due to equivalent amounts of austenite $(\gamma)$ and $\delta$-ferrite, justify their wide use in the chemical, petrochemical, nuclear, fertilizer and food industries ${ }^{3}$.

Duplex stainless steel has an unstable microstructure in the range of 300 to $1050{ }^{\circ} \mathrm{C}$ and, when subjected to these temperatures, it may undergo phase precipitation of several compounds such as chromium carbides, nitrides, sigma phase and other intermetallic phases. Service conditions at high temperature, and improper welding or fabrication processes may cause these phases to precipitate, decreasing its corrosion and mechanical properties, especially its toughness. The effects of phase precipitation at high temperatures on the mechanical and corrosion properties of duplex stainless steels have been studied extensively ${ }^{4-11}$. However, the literature offers little information about the effect of long-term thermal aging at low temperatures (300-600 ${ }^{\circ} \mathrm{C}$ ) on the corrosion resistance of duplex stainless steel.

The temperature range of 300 to $600{ }^{\circ} \mathrm{C}$ is characterized by the spinodal decomposition of ferrite into Cr-poor $\alpha$ and Cr-rich $\alpha$ ' domains, which can cause embrittlement of duplex stainless steel alloy. Investigations of 2205 duplex stainless steel by high-resolution transmission electron microscopy ${ }^{12}$ revealed that isotropic spinodal decomposition occurred during aging at $475^{\circ} \mathrm{C}$; the original $\delta$-ferrite decomposed into a nanometer-scale modulated structure with a complex interconnected network containing an iron-rich $\mathrm{BCC}$ phase $(\alpha)$ and a chromium-enriched BCC phase $\left(\alpha^{\prime}\right)$. It has been suggested ${ }^{12}$ that the locking of dislocations in the modulated structure leads to severe embrittlement.

Other precipitation processes besides $\alpha^{\prime}$ phase also occur between 300 and $600{ }^{\circ} \mathrm{C}$ in duplex stainless steel, such as $\mathrm{G}$ phase precipitation in ferrite ${ }^{13}$ and carbide ${ }^{14}$, and $\gamma_{2}$ phase precipitation at the grain boundaries ${ }^{15}$. Among these processes, the main one is $\mathrm{Ni}$, $\mathrm{Si}$, Mo-rich $\mathrm{G}$ phase precipitation ${ }^{12,16}$. These particles are very small $(1 \mathrm{~nm}$, occasionally up to $50 \mathrm{~nm})$ and are usually present in very high concentrations. They precipitate within the ferrite grain preferentially on dislocations and at $\alpha-\gamma$ interfaces. It has been reported ${ }^{17}$ that $\mathrm{G}$ phase precipitation occurs from Cr-rich $\alpha$ ' phase in the second stage of aging, which corresponds to aging of more than 3000 hours at $400{ }^{\circ} \mathrm{C}$. During this stage, the precipitated chromium-enriched phase aggregates and coarsens, and $G$ phase precipitation also occurs. TEM observations ${ }^{18}$ suggest that the kinetics of spinodal decomposition and $\mathrm{G}$ phase precipitation is influenced by the ferrite-to-austenite ratio. Thus, duplex stainless steel tempered at $475{ }^{\circ} \mathrm{C}$ and aged for 1000 hours with high ferrite content $(\alpha / \gamma=1.5)$ is characterized by a more advanced spinodal decomposition and $\mathrm{G}$ phase precipitation than steel with low ferrite content $(\alpha / \gamma=1)$

The effect of phase precipitation on the corrosion resistance of duplex stainless steel at lower temperatures ranging from 300 to $600{ }^{\circ} \mathrm{C}$ has been studied ${ }^{19,20}$ at $475{ }^{\circ} \mathrm{C}$, at which temperature alloy embrittlement is maximum. It has been reported that localized corrosion attack occurs only after a long aging period. Decreased corrosion resistance is attributed to spinodal decomposition and the resulting $\mathrm{Cr}$-rich $\alpha$ ' precipitation, which depletes $\mathrm{Cr}$ in the alloy's surrounding matrix. This susceptibility to corrosion increases as the ferrite content increases in response to spinodal decomposition 
and $\mathrm{G}$ phase precipitation, affecting the ferrite phase more than the austenite phase ${ }^{18}$.

However, the information reported in the literature does not suffice to explain the effect of aging on duplex stainless steel corrosion resistance at low temperatures, particularly from 300 to $400{ }^{\circ} \mathrm{C}$. The aim of this work is to evaluate the effect of long-term aging (3000, 5000 and 7000 hours) at 300 and $400{ }^{\circ} \mathrm{C}$ on the corrosion resistance and hardness of duplex stainless steel containing 22.5 wt. (\%) $\mathrm{Cr}$.

\section{Experimental Procedure}

The samples were taken from a hot rolled duplex stainless steel, whose composition is described in Table 1.

The samples were solubilized at $1050^{\circ} \mathrm{C}$ for 1 hour, followed by quenching in cold water at around $5{ }^{\circ} \mathrm{C}$. The resulting microstructure presented a $\alpha / \gamma$ ratio of about 50:50\%. Thermal aging treatments were conducted for 3000, 5000 and 7000 hours at temperatures of 300 and $400{ }^{\circ} \mathrm{C}$.

Corrosion properties were determined based on the weight loss test, anodic potentiodynamic polarization curves, and corrosion current density $\left(\mathrm{i}_{\text {corr }}\right)$ at room temperature $\left(25^{\circ} \mathrm{C}\right)$. The mass loss measurements were carried out in an aerated $1.7 \mathrm{M} \mathrm{FeCl}_{3}$ solution, following the ASTM G 38 standard. Each test was performed with the same sample immersed during different times and the weight loss corrosion test was performed in triplicate for each condition. The error bars correspond to the lowest and highest mass loss obtained in these three tests.

The $\mathrm{i}_{\text {corr }}$ was determined in aerated $0.1 \mathrm{M} \mathrm{H}_{2} \mathrm{SO}_{4}$ solution by the linear polarization method, using the Stern-Geary equation ${ }^{21}$.

The anodic potentiodynamic polarization curves were obtained by stepping the potential using a scan rate of $10 \mathrm{mV} / \mathrm{s}$ from $-250 \mathrm{mV}$ (SCE) to $+250 \mathrm{mV}$ (SCE) in an aerated $0.1 \mathrm{M} \mathrm{H}_{2} \mathrm{SO}_{4}$ solution at room temperature. The work electrodes were cylindrical samples $\left(0.79 \mathrm{~cm}^{2}\right.$ of exposed area), which were insulated with epoxy resin, polished with $\mathrm{SiC}$ \#600 grit sandpaper, rinsed in distilled water and immediately immersed in the test solution before each measurement. A platinum auxiliary was used and the reference electrode was a saturated calomel electrode (SCE). The electrochemical measurements were taken with a SOLARTRON 287 electrochemical system. Each polarization curve represents a coincident experiment in triplicate, according to the usual procedure.

The hardness of austenite and ferrite phases was determined by instrumented indentation, using a Nanoindenter XP (MTS System Corporation) with a Berkovich indenter (three-sided pyramid), under applied loads of 3 to $400 \mathrm{mN}$ corresponding to eight complete loading-unloading cycles. Three indentations were made on each sample. The residual indenter prints of each phase were separated using optical microscopy (Olympus BX51), and the results represent the average of the 3 indentations. Specimen surfaces were prepared for nanoindentation by mechanical polishing with SiC \#1200 sandpaper followed by polishing with $0.3 \mu \mathrm{m}$ alumina.

Structural analyses were performed using a transmission electron microscope (Philips model CM120). Thin foils for transmission electron microscope observations were prepared by preliminary mechanical thinning to a thickness of $70 \mu \mathrm{m}$, followed by dimpling up to $20 \mu \mathrm{m}$ at the center, then ion beam polishing for about 20 hours.

Table 1. Chemical composition of the DSS, wt. (\%).

\begin{tabular}{cccccccccc}
\hline Elements & $\mathrm{Cr}$ & $\mathrm{Ni}$ & $\mathrm{C}$ & $\mathrm{Mn}$ & $\mathrm{Si}$ & $\mathrm{P}$ & $\mathrm{S}$ & $\mathrm{Mo}$ & Mo \\
\hline $\begin{array}{c}\text { Content } \\
(\%)\end{array}$ & 22.6 & 5.38 & 0.024 & 1.57 & 0.35 & 0.013 & 0.008 & 2.58 & 0.13 \\
\hline
\end{tabular}

The surface of the solubilized sample and the samples aged at $300{ }^{\circ} \mathrm{C}$ for 5000 and 7000 hours were analyzed using $\mathrm{Mg}$-K $\alpha$ radiation X-ray photoelectron spectroscopy (Kratos XSAM HS). The energy of the $\mathrm{C} 1 \mathrm{~s}$ peak due to adventitious hydrocarbons was used as binding energy reference $(284.8 \mathrm{eV})$. The X-ray photoelectron spectroscopy analysis was performed after polarizing the sample in aerated $0.1 \mathrm{M}$ $\mathrm{H}_{2} \mathrm{SO}_{4}$ solution for 15 minutes at a potential in the passive region.

\section{Results}

\subsection{Corrosion resistance measurements}

Figure 1 illustrates the effect of aging time and temperature on the $\mathrm{i}_{\text {corr }}$ of the duplex stainless steel alloy samples in a $0.1 \mathrm{M} \mathrm{H}_{2} \mathrm{SO}_{4}$ solution.

The corrosion rate was directly proportional to $i_{\text {corr }}$; therefore, the results in Figure 1 indicate that the corrosion resistance of solubilized alloy changed as a function of the thermal aging treatment. As can be seen, the corrosion rate increased slightly in alloys aged for 3000 hours. However, this rate was significant after 5000 hours of aging, thereafter declining up to 7000 hours of aging, indicating that, in the conditions analyzed in this study, the highest corrosion rate occurred after 5000 hours of aging. These results also demonstrate that aging at $400{ }^{\circ} \mathrm{C}$ resulted in a higher corrosion rate than at $300{ }^{\circ} \mathrm{C}$, except for the alloy aged for 3000 hours in the $0.1 \mathrm{M} \mathrm{H}_{2} \mathrm{SO}_{4}$ solution.

Mass loss was also measured to evaluate the effect of aging time on the corrosion resistance of alloys. These measurements were obtained in a $1.7 \mathrm{M} \mathrm{FeCl}_{3}$ solution to adapt them to the experimental time. The results shown in Figure 2 confirm that the corrosion rate was highest at an aging time of around 5000 hours.

To understand the effect of aging treatment on the alloy, its passivity behavior was determined based on experimental anodic potentiodynamic polarization curves. These curves were similar to each other, indicating a behavior typical of duplex stainless steels. Figure 3 shows the curve for the sample solubilized at $1050{ }^{\circ} \mathrm{C}$ for 1 hours. Two current peaks, which indicate a region of secondary passivation, are visible in these curves. The peak current density of active-passive transition, $i_{a / p}$, occurred at a lower potential of around $100 \mathrm{mV}$ vs. SCE. The passive region occurred between $100 \mathrm{mV}$ and $900 \mathrm{mV}$ vs. SCE, while transpassivation occurred up to $1000 \mathrm{mV}$ vs. SCE. The peak current of secondary passivation occurred at a

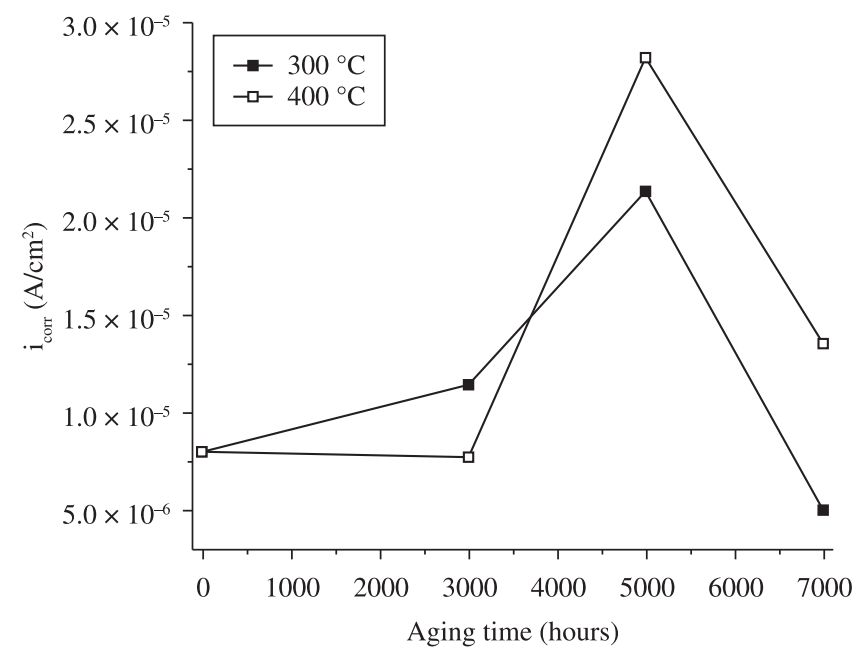

Figure 1. Effect of aging time and temperature on the corrosion current density, $\mathrm{i}_{\text {corr }}$, of 22.5 wt. (\%) Cr duplex stainless steel alloy in a $0.1 \mathrm{M} \mathrm{H}_{2} \mathrm{SO}_{4}$ solution at room temperature. 
higher potential of around $1250 \mathrm{mV}$ vs. SCE. The region of secondary passivation extended up to the potential of $1500 \mathrm{mV}$ vs. SCE, at which point oxygen evolution occurred.

The intensity of the peak current density of the active-passive transition and secondary passivation was attributed to the alloy's facility to form a passive film and a secondary passive film, respectively. Thus, the lower intensity of this peak current density led to higher passivation. The partial anodic potentiodynamic polarization curves in Figure 4 show the presence of the peak current density of the active-passive transition, $\mathrm{i}_{\mathrm{a} / \mathrm{p}}$ at 300 and $400{ }^{\circ} \mathrm{C}$.

Figure 5 illustrates the peak current densities, $i_{a / p}$, shown in Figure 4 as a function of aging time. This behavior is affected by the aging temperature. The behavior of the current density of the active-passive transition peak indicates that the aging time of the samples treated at $400{ }^{\circ} \mathrm{C}$ increased up to 5000 hours, preventing the occurrence of passivation. However, 7000 hours of aging decreased the peak current density. The effect of aging time on the peak current density was not clear in the sample aged at $300{ }^{\circ} \mathrm{C}$.

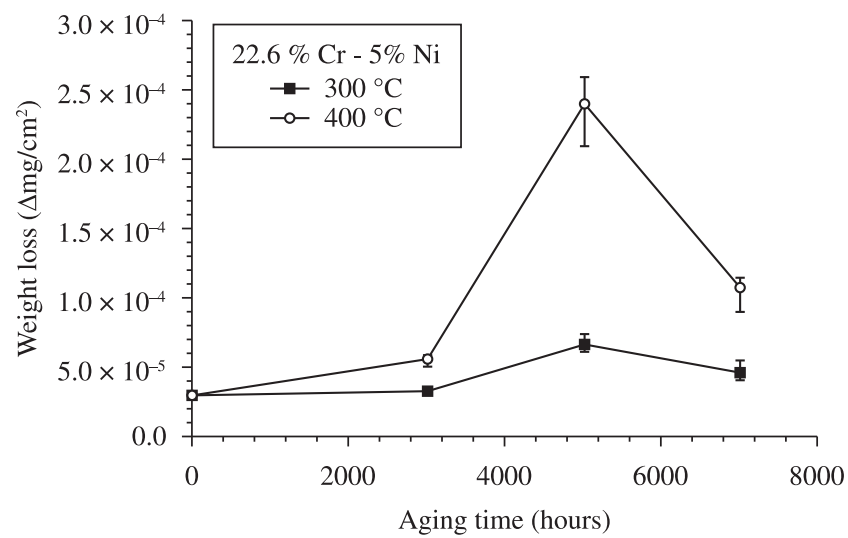

Figure 2. Weight loss $\left(\mathrm{g} . \mathrm{cm}^{-2}\right)$ as a function of aging time. Solution: $1.7 \mathrm{M}$ $\mathrm{FeCl}_{3}$ for 200 hours.

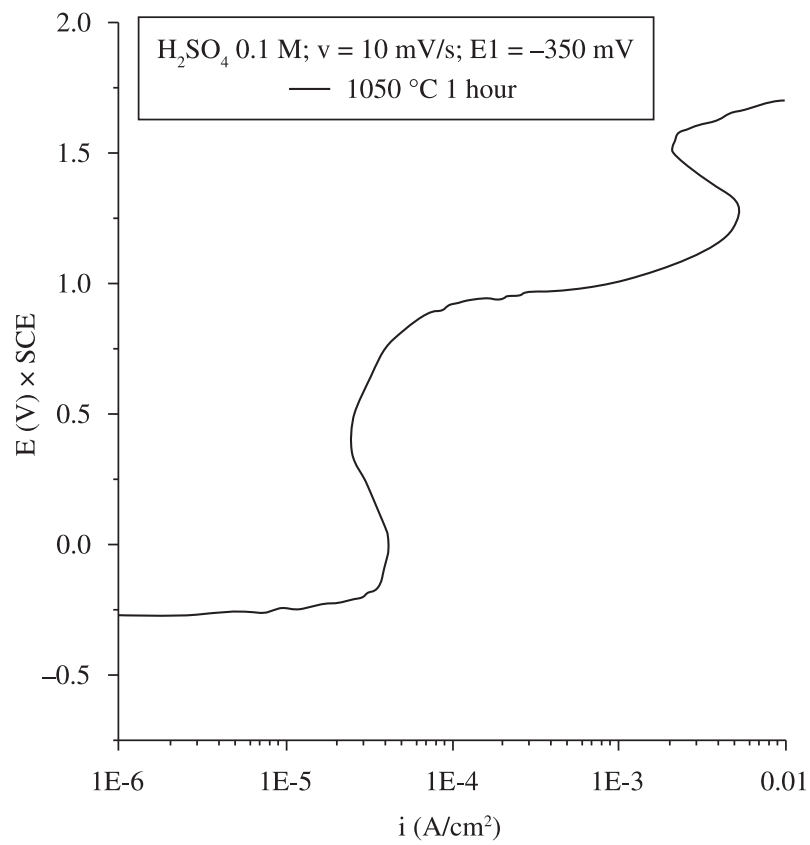

Figure 3. Typical anodic potentiodynamic polarization curve of the duplex stainless steel solubilized at $1050{ }^{\circ} \mathrm{C}$ for 1 hour. Solution: $\mathrm{H}_{2} \mathrm{SO}_{4} 0.1 \mathrm{M}$, $\mathrm{v}=10 \mathrm{mV} / \mathrm{s}$.

\subsection{Hardness tests}

The effect of aging on the corrosion resistance of the alloy under study can probably be ascribed to microstructural changes. To understand these changes, the effect of aging conditions on the hardness of the samples was investigated.

Figure $6 \mathrm{a}$ and $6 \mathrm{~b}$ shows the hardness of ferrite and austenite phases, and the global hardness of the alloy as a function of the aging heat-treatment conditions. The global hardness represents the average hardness of ferrite and austenite phases.

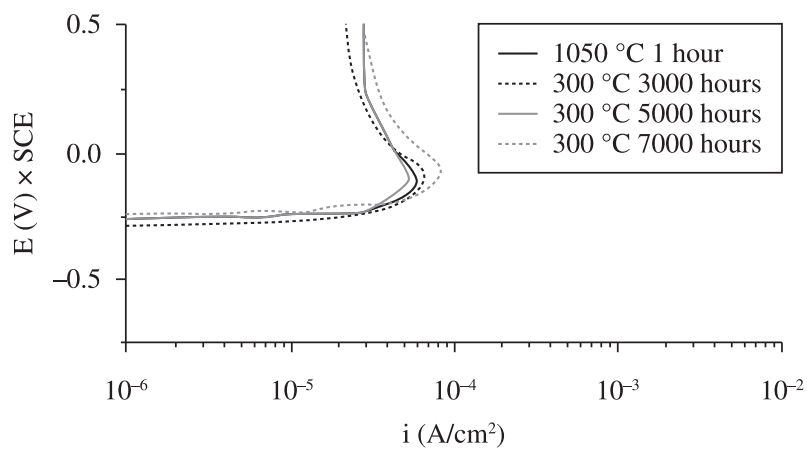

(a)

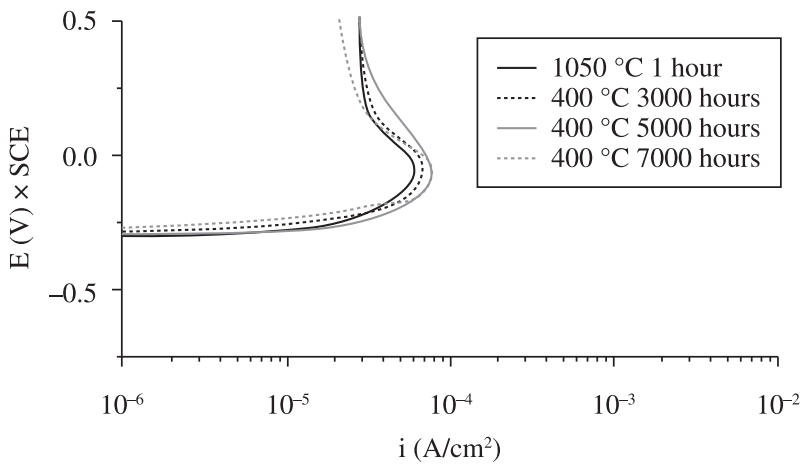

(b)

Figure 4. Partial anodic potentiodynamic curves, with the presence of a current density peak of active-passive transition, $i_{v / p}$, in the duplex stainless steel aged under different conditions of time and temperature. Solution: $\mathrm{H}_{2} \mathrm{SO}_{4} 0.1 \mathrm{M}$, $\mathrm{v}=10 \mathrm{mV} / \mathrm{s}$. a) Aging at $300{ }^{\circ} \mathrm{C}$ and b) aging at $400{ }^{\circ} \mathrm{C}$.

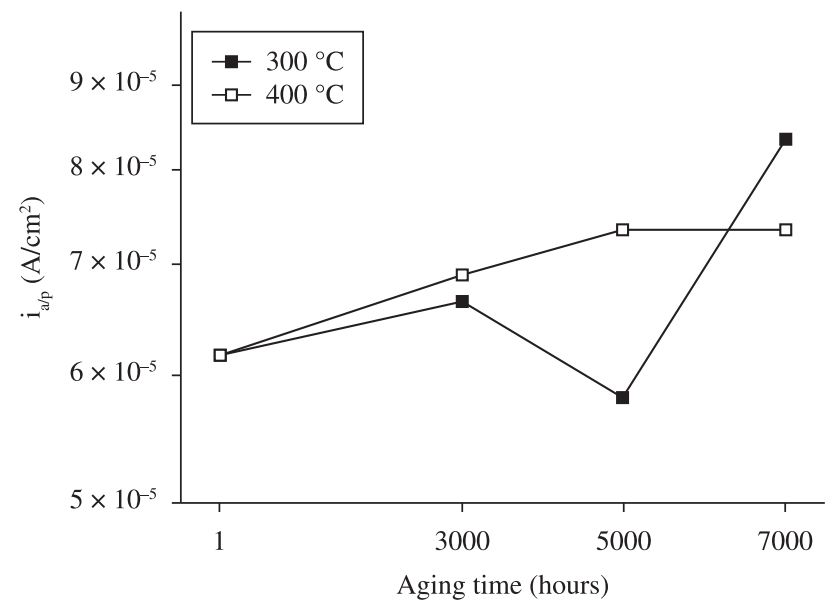

Figure 5. Critical current density at the peak as a function of aging time and temperature in duplex stainless steel alloy in $0.1 \mathrm{M} \mathrm{H}_{2} \mathrm{SO}_{4}$ solution. 


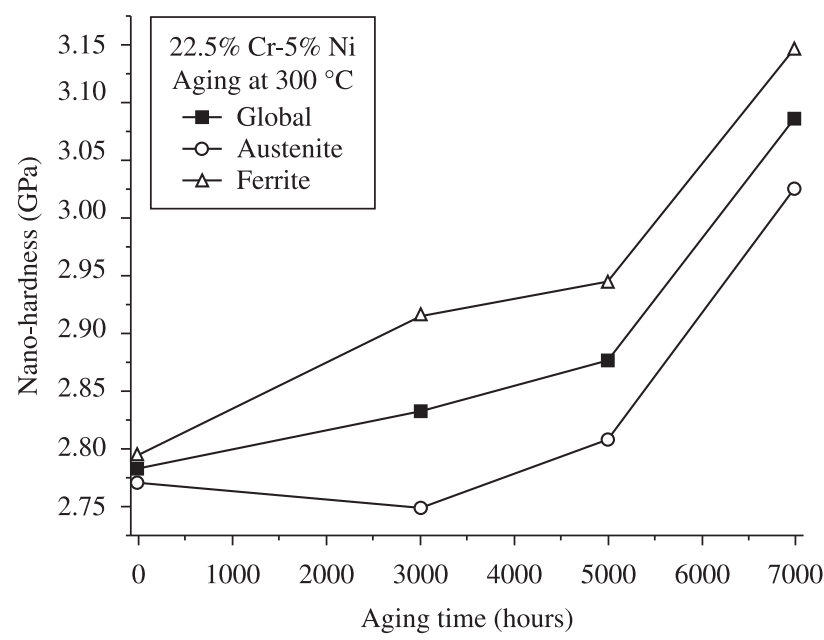

(a)

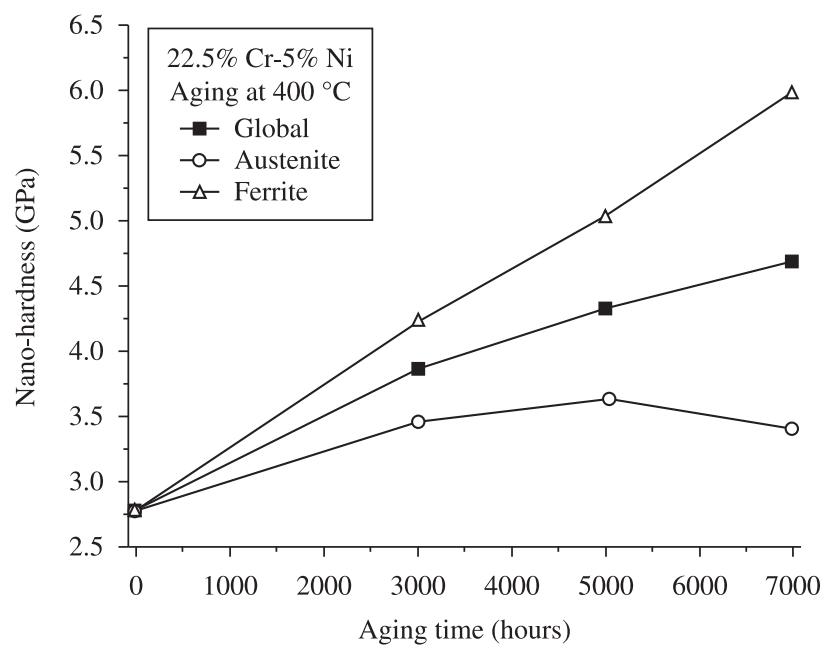

(b)

Figure 6. Effect of aging time on the overall hardness and nanohardness of ferrite and austenite phases: a) Aging at $300{ }^{\circ} \mathrm{C}$ and b) aging at $400{ }^{\circ} \mathrm{C}$. Error: \pm 0.10 .

Figure $6 \mathrm{a}$ and $6 \mathrm{~b}$ indicates that the global hardness increased with advancing aging time. The hardness also increased along with aging temperature. This effect of thermal aging on the alloy's hardness occurs in response to phase changes that take place during heat treatments, which are related to the effect of aging on corrosion resistance.

Figure $6 \mathrm{a}$ and $6 \mathrm{~b}$ also shows that global hardness was changed mainly by the ferrite phase. The effect of aging time on the hardness of austenite was less significant than on that of the ferrite phase.

\subsection{Structural analysis by transmission electron microscopy (TEM)}

The purpose of the TEM analysis was to correlate the effect of aging treatments with the morphology of the duplex stainless steel alloys. Figures 7 show TEM images of the microstructures of samples aged at $400{ }^{\circ} \mathrm{C}$ for 3000 hours.

Figure 7 shows the presence of a discontinuous phase indicating the possible presence of precipitates. Note that the precipitates occur next to dislocations; hence, it is possible that this precipitate corresponds to the $\mathrm{G}$ phase, which occurs in ferrite phase associated with the dislocation ${ }^{16}$. However, this discontinuous phase must be analyzed, which will be done in future work.

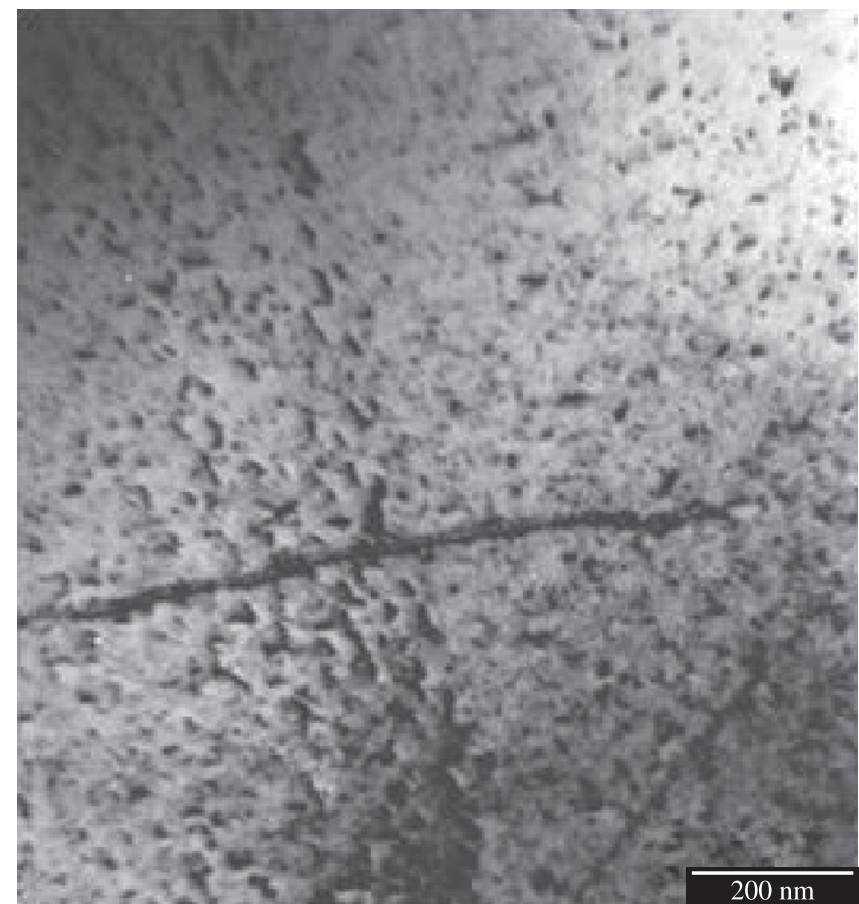

Figure 7. TEM analysis of duplex stainless steel alloy aged for 3000 hours at $300{ }^{\circ} \mathrm{C}$, bright field.

\subsection{X-ray photoelectron spectroscopy (XPS) analysis}

Figure 8 shows the effect of aging on the composition of the passive film of the alloy aged at $300{ }^{\circ} \mathrm{C}$. This figure shows the mass percent of iron and chromium oxide in relation to passive film mass. The mass percent of oxide iron was calculated from the Equation 1:

$$
\frac{F e_{\text {oxidized }}}{C r_{\text {oxidized }}+F e_{\text {oxidized }}}
$$

while the mass percent of oxidized chromium was calculated from the Equation 2:

$$
\frac{C r_{\text {oxidized }}}{C r_{\text {oxidized }}+F e_{\text {oxidized }}}
$$

The XPS analysis indicated that the aging time exerts an inverse effect on the oxidized iron and oxidized chromium content in passive film. Aging for 5000 hours decreased the oxidized chromium in passive film, but its content increased with 7000 hours of aging.

\section{Discussion}

Our findings revealed that the aging treatment significantly affects the corrosion resistance of the duplex stainless steel alloy. This effect was probably caused by phase transitions occurring during aging, which is coherent with the hardness, TEM and XPS measurements.

According to the literature, precipitation of $\mathrm{G}^{17}$ and $\alpha^{\prime 22}$ phases can occur in duplex stainless steels aged at temperatures of 300 and $400{ }^{\circ} \mathrm{C}$. It is possible that aging duplex stainless steel alloy for long periods causes the ferrite to decompose into $\mathrm{Cr}\left(\alpha^{\prime}\right)$ and $\mathrm{Fe}(\alpha)$ rich phases. This phase transition is due to the compositional changes that favor $\mathrm{G}$ phase precipitation ${ }^{23}$. Experimental TEM results of the sample aged at $300{ }^{\circ} \mathrm{C}$ indicate the likely presence of $\mathrm{G}$ phase. These phases are rich in elements that can affect the alloy's corrosion resistance and mechanical properties. 


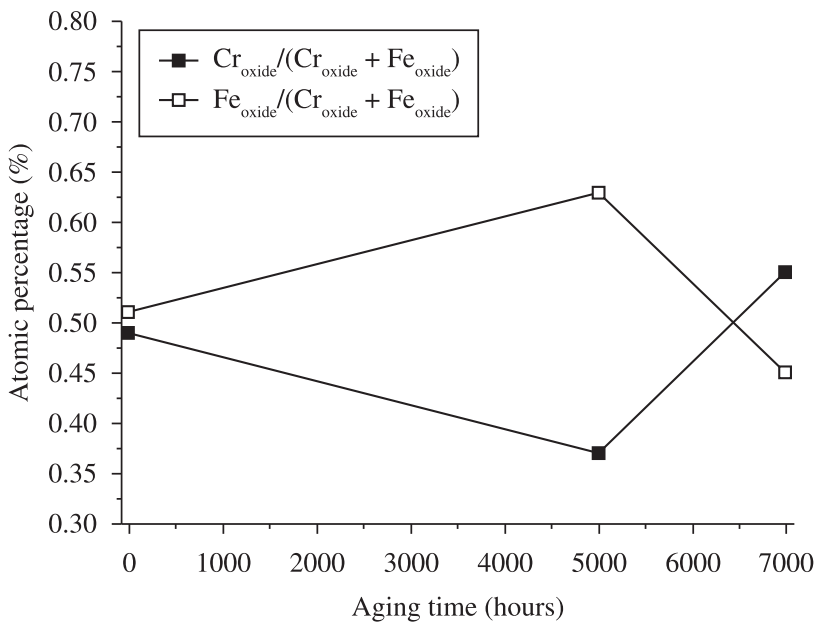

Figure 8. Composition of the oxide layer analyzed by XPS of duplex stainless steel alloy aged at $300{ }^{\circ} \mathrm{C}$.

The $\alpha$ ' phase is rich in $\mathrm{Cr}$, while the $\mathrm{G}$ phase presents higher $\mathrm{Cr}$, $\mathrm{Ni}$, Mo and Si content than the matrix ${ }^{23}$. This behavior is coherent with the XPS results shown in Figure 8. These results indicate that 3000 hours of aging, which probably results in the formation of precipitates, decreased the oxidized chromium in passive film, indicating the presence of less $\mathrm{Cr}$ in the matrix. This reduction of $\mathrm{Cr}$ in passive film is probably related to the higher $\mathrm{Cr}$ content in the precipitate, resulting in $\mathrm{Cr}$ depletion in the proximities of precipitates and, in consequence, the lower amount of this element in the matrix.

As previously reported ${ }^{20}$, the aging of a $29.4 \mathrm{Cr}-8.7 \mathrm{Ni}-0.41 \mathrm{Si}$ duplex stainless at $400{ }^{\circ} \mathrm{C}$ caused depletion of silicon in the ferrite phase, mainly due to the precipitation of silicon-rich phases such as $G$ phase. The increased volumetric fraction of $G$ phase with progressive aging has already been reported in duplex stainless steel $^{23}$. These results show that the volumetric fraction of $\mathrm{G}$ phase in samples treated at $350{ }^{\circ} \mathrm{C}$ increased from 40 to $60 \%$ at aging times of 1000 and 3000 hours, respectively.

Therefore, the decrease in corrosion resistance of both alloys with aging time, which was observed in a $0.1 \mathrm{M} \mathrm{H}_{2} \mathrm{SO}_{4}$ solution after 5000 hours, can be ascribed to phase precipitation occurring during aging. The precipitation of these phases resulted in regions depleted of elements as such the $\mathrm{Cr}$ and affected the corrosion resistance of the alloy in the proximities of the phase/matrix interface, leading to a galvanic corrosion effect between the alloy-depleted region and the alloy matrix. This hypothesis is coherent with the results of XPS measurements of the Fe-22.5Cr alloy shown in Figure 8, which indicate that the $\mathrm{Cr}$ oxidized content diminished in the passive film at 5000 hours of aging, indicating a decline in the content of this element.

The higher corrosion resistance of the alloy in a $0.1 \mathrm{M} \mathrm{H}_{2} \mathrm{SO}_{4}$ solution after 7000 hours of aging than that of alloy aged for 3000 and 5000 hours can be attributed to phase coarsening and/or the "healing" effect of longer aging times. It is possible that 7000 hours of aging enhances the size of phase precipitates due to coarsening. Thus, the phase/matrix interface area per volume, and hence, the area of the alloy-depleted regions decreased, minimizing the corrosion rate. It is also possible that in addition to coarsened phases, long aging periods such as 7000 hours promote the "healing" effect that results in chromium equalization. This effect, which has been observed in stainless steel containing chromium carbide and subjected to thermal treatment ${ }^{24}$, corresponds to the disappearance of chromium depleted zones around precipitated phases due to the diffusion of chromium in the matrix.
The minimized chromium-depleted zones around precipitated phases after 7000 hours of aging when compared with the sample aged for 5000 hours are also consistent with the XPS measurements depicted in Figure 8, which shows the presence of a larger amount of chromium in the passive film of the sample aged for 7000 hours.

The effect of aging time on the current density of the active-passive transition peak, $\mathrm{i}_{\mathrm{a} / \mathrm{p}}$, determined from the polarization curves (Figure 4) in a $\mathrm{H}_{2} \mathrm{SO}_{4}$ solution, may also be related to the phase changes that occurred during aging. The growth of this peak in samples heat-treated at $400{ }^{\circ} \mathrm{C}$ and aged for up to 5000 hours can be attributed to the increased area of matrix/phase interfaces, and therefore, of the area of alloy-depleted regions at these interfaces, which hindered the passivation process. The increase of $i_{a / p}$ in response to 7000 hours of aging may be attributed to the diminished area of alloy-depleted regions resulting from chromium coalescence and/or equalization. However, in the sample aged at $400{ }^{\circ} \mathrm{C}$, the effect of aging time on the $\mathrm{i}_{\mathrm{a} / \mathrm{p}}$ in a $\mathrm{H}_{2} \mathrm{SO}_{4}$ solution could not be unequivocally ascribed to the effect of aging time on the $i_{\text {corr }}$.

The correlation between the decrease in corrosion resistance after 3000 and 5000 hours of aging and the precipitated phase is consistent with the hardness of aged alloys shown in Figure 6. The precipitated phases act as barriers against dislocation motion, resulting in increased hardness of the alloy. The possible increases in the volumetric fraction of precipitates in response to 3000 and 5000 hours of aging augment the alloy's hardness. The possible coarsening of precipitates caused by 7000 hours of aging decreases the surface area of precipitates, and hence, the area per unit volume of the barriers to dislocation motion. This effect should reduce the alloy's hardness.

However, the results show that 7000 hours of aging reduced the alloy's corrosion resistance but not its hardness. The increase in hardness after 7000 hours of aging indicates that this treatment increased the area per unit volume of the barriers to dislocation motion, probably due the high nucleation rate. Therefore, it is possible that the increase in corrosion resistance resulting from 7000 hours of aging was related mainly to the diffusion of chromium from the matrix to the chromium-depleted area, which probably did not affect the material's hardness.

The fact of that effect of aging time on the hardness of austenite was less significant than on that of the ferrite phase indicates that precipitation occurred mainly in ferrite phase.

The lower corrosion resistance of alloy aged at $400{ }^{\circ} \mathrm{C}$ than of that aged at $300{ }^{\circ} \mathrm{C}$, except for the alloy aged for 3000 hours in a $0.1 \mathrm{M}$ $\mathrm{H}_{2} \mathrm{SO}_{4}$ solution was likely related to the area of the matrix/precipitate interface. It is possible that aging at $400{ }^{\circ} \mathrm{C}$ increases the phase nucleation rate, thus increasing the area of alloy-depleted regions at the precipitate/matrix interface. This effect was confirmed by the hardness measurements, which indicated that the alloy's hardness was greater when aged at $400{ }^{\circ} \mathrm{C}$ than at $300{ }^{\circ} \mathrm{C}$.

\section{Conclusions}

Long-term aging (3000, 5000 and 7000 hours) at 300 and $400{ }^{\circ} \mathrm{C}$ significantly affected the corrosion resistance of 22.5 wt. (\%) $\mathrm{Cr}$ content duplex stainless steel alloy. This effect was caused by phase transitions after aging.

The alloy's corrosion resistance in the $0.1 \mathrm{M} \mathrm{H}_{2} \mathrm{SO}_{4}$ and $1.7 \mathrm{M}$ $\mathrm{FeCl}_{3}$ solutions decreased continually up to 5000 hours of aging. However, longer aging periods of 7000 hours increased the corrosion resistance when compared to samples aged for 3000 and 5000 hours.

The XPS analysis showed that 5000 hours of aging reduced the chromium oxide content in the passive film, but that this content increased after aging for 7000 hours. G phase precipitation was identified by transmission electron microscopy. The alloy aged for 
7000 hours contained larger precipitates than the alloy aged for 5000 hours, probably indicating that 7000 hours of aging led to coarsening of phase precipitates.

The hardness of the alloy under study increased in response to the thermal aging treatment. This effect occurred mainly in the ferrite phase and was ascribed to phase precipitation during aging.

\section{References}

1. Widmark H. Thirty years of stainless steel development. Scandinavian Journal of Metallurgy. 1993; 22:156-164.

2. Olsson J and Snis M. Duplex - A new generation of stainless steels for desalination plants. Desalination. 2007; 205:104-113.

3. Dupoiron F and Aoudouard JP. Duplex Stainless steel: a high mechanical properties stainless steel family. Scandinavian Journal of Materials. 1996; 25:95-102.

4. Xiang $\mathrm{H}, \mathrm{He} \mathrm{F}$ and Liu D. Effects of aging temperature on precipitation phase of a cast super duplex stainless steel. Acta Metallurgica Sinica. 2009; 45:1456-1460.

5. Han D, Jiang Y, Deng B, Zhang L, Zhang W and Li J. Effect of aging time on electrochemical corrosion behavior of 2101 duplex stainless steel. Acta Metallurgica Sinica. 2009; 45:919-923.

6. Deng B, Wang Z, Jiang Y and Wang H. Evaluation of localized corrosion in duplex stainless steel aged at $850^{\circ} \mathrm{C}$ with critical pitting temperature measurement. Electrochemical Acta, 2009; 54:2790-2794.

7. Zhang L, Jiang Y, Deng B, Zhang W, Xu J and Li J. Effect of aging on the corrosion resistance of 2101 lean duplex stainless steel. Materials Characterization. 2009; 60:1522-1528.

8. Ghosh SK and Mondal S. High temperature ageing behavior of a duplex stainless steel. Materials Characterization. 2008; 60:1776-1783.

9. Chen TH and Yang JR. Effects of solution treatment and continuous cooling on $\sigma$-phase precipitation in a SAF 2205 duplex stainless steel. Materials Science and Engineering A. 2001; 311A:28-41.

10. Magnabosco R. Kinetics of sigma phase formation in a duplex stainless steel. Materials Research. 2009; 12:321-327.

11. Escriba DM, Materna-Morris E, Plaut RL and Padilha AF. Chi-phase precipitation in a duplex stainless steel. Materials Characterization. 2009; 60:1215-1219.
12. Weng KL, Chen HR and Yang JR. The low-temperature aging embrittlement in a 2205 duplex stainless. Materials Science and Engineering A, 2004; 379:119.

13. David SA, Vitec JM and Alexander DJ. Embrittlement of austenitic stainless steels welds. Journal Nondestructive Evaluation. 1996; 15:129.

14. Vitek JM, David SA, Alexander DJ, Keiser JR and Nanstad RK. Low Temperature Aging Behavior of Type 308 Stainless Steel Weld Metal. Acta Metallurgica et Materialia. 1991; 39:503-516.

15. Hu ZW, Hsu SS and Jiang XL. HREM Study on alpha-L and Gama-2 Precipitation in an aged wrought duplex stainless steel at 500 - degrees - C. Scripta Metallurgical. 1991; 25:645-650.

16. Miller MK and Bentley J. APFIN and AEM investigation of CF8 and CF8M primary coolant pipe steel. Material Science Technology. 1990; 6:285-292.

17. Yamada T, Okano $\mathrm{S}$ and Kuwano H. Mechanical properties and microstructural change by thermal aging of SCS14A cast duplex stainless steel. Journal of Nuclear Materials. 2006; 350:47-55.

18. Iacoviello F, Casari F and Gialanela S. Effect of 475 degrees C embrittlement on duplex stainless steel localized corrosion resistance. Corrosion Science. 2005; 47:909-922.

19. Tavares SSM, Terra VF, De Lima Neto P and Matos DE. Corrosion resistance evaluation of the UNSS31803 duplex stainless steels aged at low temperatures ( 350 to 550 degrees C) using DLEPR tests. Journal of Materials Science. 2005; 40:4025-4028.

20. May JE, Sousa CAC and Kuri SE. Aspects of anodic behavior of duplex stainless steels aged for long periods at low temperatures. Corrosion Science. 2003; 45:1395-1403.

21. Stearn M and Geary L. A Method for Determining Corrosion Rates From Linear Polarization Rates. Corrosion. 1958; 14:60-64.

22. Nilsson JO and Liu P. Aging at $400-600^{\circ} \mathrm{C} 22 \mathrm{Cr}-3 \mathrm{Mo}-8 \mathrm{Ni}$ duplex stainless steel and its effect on toughness and microstructure. Materials Science Technology. 1991; 7:853-862.

23. Danoix F and Auger P. Atom probe studies of the $\mathrm{Fe}-\mathrm{Cr}$ system and stainless steels aged at intermediate temperature. Materials Characterization. 2000; 44:177-201.

24. Sendriks AJ. Corrosion of Stainless Steels. $2^{\text {nd }}$ ed. New York: J. Wiley \& Sons; 1996. 